\title{
GRAVITY MONITORING OF $\mathrm{CO}_{2}$ MOVEMENT DURING SEQUESTRATION: MODEL STUDIES
}

E. Gasperikova ${ }^{1}$ and G.M. Hoversten ${ }^{1,2}$

${ }^{1}$ Lawrence Berkeley National Laboratory, One Cyclotron Road, MS-90R1116, Berkeley, CA94720, egasperikova@lbl.gov, 510-486-4930

${ }^{2}$ Chevron-Texaco, 6001 Bollinger Canyon Road, San Ramon, CA 94583, HOVG@chevron.com

Gravity monitoring of $\mathrm{CO}_{2}$ movement

\begin{abstract}
We examine the relative merits of gravity measurements as a monitoring tool for geological $\mathrm{CO}_{2}$ sequestration in three different modeling scenarios. The first is a combined $\mathrm{CO}_{2}$ enhanced oil recovery (EOR) and sequestration in a producing oil field, the second is sequestration in a brine formation, and the third is for a coalbed methane formation. EOR/sequestration petroleum reservoirs have relatively thin injection intervals with multiple fluid components (oil, hydrocarbon gas, brine, and $\mathrm{CO}_{2}$ ), whereas brine formations usually have much thicker injection intervals and only two components (brine
\end{abstract}


and $\left.\mathrm{CO}_{2}\right)$. Coal formations undergoing methane extraction tend to be thin $(3-10 \mathrm{~m})$, but shallow compared to either EOR or brine formations. The injection of $\mathrm{CO}_{2}$ into the oil reservoir produced a bulk density decrease in the reservoir. The spatial pattern of the change in the vertical component of gravity $\left(G_{z}\right)$ is directly correlated with the net change in reservoir density. Furthermore, time-lapse changes in the borehole $\mathrm{G}_{\mathrm{z}}$ clearly identified the vertical section of the reservoir where fluid saturations are changing. The $\mathrm{CO}_{2}$-brine front, on the order of $1 \mathrm{~km}$ within a $20 \mathrm{~m}$ thick brine formation at $1900 \mathrm{~m}$ depth, with $30 \% \mathrm{CO}_{2}$ and $70 \%$ brine saturations, respectively, produced a -10 Gal surface gravity anomaly. Such anomaly would be detectable in the field. The amount of $\mathrm{CO}_{2}$ in a coalbed methane test scenario did not produce a large enough surface gravity response; however,

we would expect that for an industrial size injection, the surface gravity response would be measurable. Gravity inversions in all three scenarios illustrated that the general position of density changes caused by $\mathrm{CO}_{2}$ can be recovered, but not the absolute value of the change. Analysis of the spatial resolution and detectability limits shows that gravity measurements could, under certain circumstances, be used as a lower-cost alternative to seismic measurements.

\section{INTRODUCTION}

Cost effective monitoring of reservoir fluid movement during $\mathrm{CO}_{2}$ sequestration is a necessary part of a practical geologic sequestration strategy. Seismic techniques are well developed for monitoring production in petroleum reservoirs. The cost of time-lapse seismic monitoring in such cases is justified, because it is small compared to the profits 
from the hydrocarbon production. However, the cost of seismic monitoring techniques is more difficult to justify in an environment of sequestration, where the process produces no direct profit. Therefore, other geophysical techniques such as gravity, which might provide sufficient monitoring resolution at a significantly lower cost, need to be considered.

Petroleum reservoirs have the natural advantages of being already well characterized, having a demonstrated seal, having an existing infrastructure, and offering cost offsets in the form of enhanced petroleum production as $\mathrm{CO}_{2}$ is injected. From a monitoring standpoint, petroleum reservoirs offer more challenges than brine formations because they typically have less vertical extent, and have multiple in situ fluids (oil, hydrocarbon gas, brine, and $\mathrm{CO}_{2}$ ). Brine formations usually have much thicker potential injection intervals and only two components (brine and $\mathrm{CO}_{2}$ ). However, they would need to be characterized, and an infrastructure for injection and monitoring $\mathrm{CO}_{2}$ would have to be built. Coal formations undergoing methane extraction will tend to be thin ( 3 to $10 \mathrm{~m}$ ) but shallow compared to either petroleum reservoirs or brine formations. In this paper, we consider the time-lapse performance of gravity monitoring, using models derived from reservoir flow simulations of three $\mathrm{CO}_{2}$ sequestration scenarios in: (1) an oil reservoir, (2) a brine formation, and (3) a depleted coalbed methane formation.

Gravity methods are sensitive to density change. The density of $\mathrm{CO}_{2}$, typical reservoir fluids, and various combinations of both can be easily calculated (NIST14, 1992); thus, it is possible to assess expected changes in geophysical properties. For most of the depth interval of interest for sequestration, $\mathrm{CO}_{2}$ is less dense and more compressible than brine or oil, and less dense than coal; consequently, gravity methods 
are reasonable candidate methods for brine, oil-bearing formations or depleted coalbed methane reservoirs.

The bulk rock density $\mathrm{D}_{\text {bulk }}$ of the reservoir is calculated using:

$$
\mathrm{D}_{\text {bulk }}=\left(1-\mathrm{S}_{\mathrm{w}}-\mathrm{S}_{\mathrm{CO}_{2}}\right) \mathrm{D}_{\text {grain }}+\mathrm{S}_{\mathrm{w}} \mathrm{D}_{\text {brine }}+\mathrm{S}_{\mathrm{CO}_{2}} \mathrm{D}_{\mathrm{CO}_{2}}
$$

where $\mathrm{S}_{\mathrm{w}}$ is the brine saturation, $\mathrm{S}_{\mathrm{CO} 2}$ is the $\mathrm{CO}_{2}$ saturation, $\mathrm{D}_{\text {grain }}$ is the grain density, $\mathrm{D}_{\text {brine }}$ is the brine density, and $\mathrm{D}_{\mathrm{CO} 2}$ is the $\mathrm{CO}_{2}$ density. We neglect the density effect of $\mathrm{CO}_{2}$ dissolved in the brine; the grain density depends on reservoir formation.

The feasibility of any geophysical technique depends not only on the inherent resolution of the technique, but on the magnitude of the change in the measured geophysical properties produced by increasing the $\mathrm{CO}_{2}$ concentration. Hence, calculating the expected gravity response of different models is an essential part of a survey design. We calculate responses for three sequestration scenarios, and discuss when the use of gravity monitoring is appropriate.

Inversion of gravity data is very important, since construction of density contrast models significantly increases the amount of information that can be extracted from the gravity data. However, one substantial difficulty with the inversion of gravity data is its inherent non-uniqueness and lack of inherent depth resolution. This difficulty can be overcome by introduction of a priori information. We adopted the approach described by Smith et al. (1999) for magnetotelluric data inversion, in which the top and base of the reservoir are known, and we invert for a smooth density variation inside the reservoir. The inversion result is a cumulative density change in the reservoir as a function of $\mathrm{x}$ and y coordinates. We discuss inversion results for each scenario separately. 


\section{EOR/SEQUESTRATION MODEL}

The enhanced oil recovery (EOR)/sequestration reservoir in our model was a sandstone unit with about $30 \%$ porosity and $25-30 \mathrm{~m}$ thickness, at a depth of $1150-1350$ m. Time-lapse models of the reservoir were run at initial conditions and seven 5-year increments. In this paper, we show only the change caused by $\mathrm{CO}_{2}$ injection over 20 years. A rock properties model, developed from log data, related reservoir parameters to geophysical parameters and aided in converting flow-simulation model parameters to geophysical parameters. The time-lapse measurements of the reservoir were used to produce time-lapse changes in geophysical properties that can be related to the movement of $\mathrm{CO}_{2}$ within the injection interval. A water-after-gas (WAG) injection strategy was considered, which produces complicated spatial variations in both $\mathrm{CO}_{2}$ saturation $\left(\mathrm{S}_{\mathrm{CO} 2}\right)$ and brine saturation $\left(\mathrm{S}_{\mathrm{w}}\right)$ within the reservoir over time.

In general, since at reservoir conditions $\mathrm{CO}_{2}$ is less dense than either oil or water, the addition of $\mathrm{CO}_{2}$ to the reservoir causes a reduction in the measured gravitational attraction either at the surface or in a borehole. (We assume that porosity does not vary as gas is injected.) Net density changes within the reservoir over 20 years of $\mathrm{CO}_{2}$ injection are shown in Figure 1a, while net changes of $\mathrm{CO}_{2}$ saturation are shown in Figure $1 \mathrm{~b}$. A WAG injection strategy produces complicated spatial variations in water and $\mathrm{CO}_{2}$ saturations, and in turn variations in net density within the reservoir over time. Cool colors (blue) represent density increase and low $\mathrm{S}_{\mathrm{CO} 2}$, whereas warm colors (red, yellow, green) represent density decrease and high $\mathrm{S}_{\mathrm{CO} 2}$. Black symbols indicate injection well locations. Gasperikova and Hoversten (2006) showed that the time-lapse change in the 
vertical attraction of gravity $\left(\mathrm{G}_{\mathrm{z}}\right)$ at the ground surface caused by the change in $\mathrm{CO}_{2}$ saturation after 20 years was on the order of $3 \mu \mathrm{Gal}$, which is right at the level of repeatability for a field survey using current technology (Hare et al., 1999; Brown et al., 2003). Note that brine formations, which are generally thicker than petroleum reservoirs, would at the same depths produce measurable responses. This was the experience at the Sleipner $\mathrm{CO}_{2}$ project (Nooner et al., 2003) for a gravity survey conducted in 2002.

Access to boreholes allows gravity measurements to be made closer to the reservoir, thus strengthening the signal compared to observations made on the surface. We calculated the response at a depth of $1200 \mathrm{~m}$ (10-100 $\mathrm{m}$ above the reservoir). As expected, the calculated magnitude of change in $G_{z}$ was larger than for surface measurements and measurable in the boreholes with current commercial technology (Thomsen et al., 2003). However, access exclusively through the existing injection wells would substantially reduce the data coverage. Figure 2 shows a map of contoured changes in $\mathrm{G}_{\mathrm{z}}$ measured only in the 22 injection wells at a depth of $1200 \mathrm{~m}$. Warm colors represent a decrease in $\mathrm{G}_{\mathrm{z}}$ due to presence of $\mathrm{CO}_{2}$, while cool colors represent an increase in $\mathrm{G}_{\mathrm{z}}$ due to presence of water.

In general, interpretation of the interpolated $\mathrm{G}_{\mathrm{z}}$ changes from the existing 22 boreholes would lead to an overestimate of the $\mathrm{CO}_{2}$ saturation changes in the reservoir. This problem is particularly evident at the north end of the reservoir, where increased $\mathrm{CO}_{2}$ saturation at two isolated wells produces an interpolated image that would be interpreted as increased $\mathrm{CO}_{2}$ between the wells where no $\mathrm{CO}_{2}$ exists. Borehole measurements need to be used in conjunction with some form of surface measurement to guide the interpolation between wells. Alternatively, pressure testing between wells could 
provide estimates of spatial variations in permeability that could be used to condition, in a statistical sense, the interpolation of the borehole gravity data. Many possibilities exist for combining borehole data with other information to produce more accurate maps of change within the reservoir.

The inversion result of $\mathrm{G}_{z}$ data measured in 22 wells at a depth of $1200 \mathrm{~m}$ is shown in Figure 3, in the form of a cumulative density change as a function of $\mathrm{x}$ and $\mathrm{y}$ coordinates. Again, warm colors represent a density decrease, whereas cool colors represent a density increase and black symbols indicate well locations. The inversion used the top and the bottom of the reservoir as a priori information. The cell size used for a reservoir density model in the inversion domain was $500 \times 500 \times$ reservoir thickness (m). The choice of the cell size is governed by the spacing between the observation wells (which averages 2-3 km), in an attempt to reduce overparameterization of the inverse problem.

The inversion recovers locations with increased $\mathrm{CO}_{2}$ saturation accurately, except in the area running northwest-southeast in the north part of the field, where no boreholes were present. The magnitude of density variation close to the wells recovered by inversion is close to the true value. However, as the distance from the observation wells increases, the constraint on the possible density variation decreases. This coupled with the smoothing constraint of the inversion, acts to produce density variations that, in general, have a lower magnitude than found in the true model. The complex nature of the true density variations, with both positive and negative variations, allows many smooth models of lower amplitude variations, which fit the observed data equally well. Although the magnitude of the density variations recovered by inversion are too low, the spatial 
distribution of positive and negative changes in density are highly correlated with the true variations, and thus can be used to interpret the spatial distribution of $\mathrm{CO}_{2}$ in the reservoir. In the future, if borehole gravity measurements can be combined with additional information to produce a more accurate interpolated map of $\mathrm{G}_{\mathrm{z}}$, the inversion result would improve the density distribution throughout the entire field.

In addition to considering spatial variations in $G_{z}$, both on the surface and at a single depth within boreholes, we calculated the response of $\mathrm{G}_{\mathrm{z}}$ in vertical profiles down boreholes. Figure $4 \mathrm{a}$ and $4 \mathrm{~b}$ are the changes in $\mathrm{S}_{\mathrm{w}}$ and $\mathrm{S}_{\mathrm{CO} 2}$, respectively, over 20 years of $\mathrm{CO}_{2}$ injection along a vertical slice through the reservoir at one injection well. At the top of the reservoir near the injection well, $\mathrm{S}_{\mathrm{w}}$ decreases while $\mathrm{S}_{\mathrm{CO} 2}$ increases. At the bottom of the reservoir, both $\mathrm{S}_{\mathrm{CO} 2}$ and $\mathrm{S}_{\mathrm{w}}$ increase slightly. The difference in $\mathrm{G}_{\mathrm{z}}$ calculated from measured $G_{z}$ in the borehole before and after injection, shown in Figure 5, reflects this change by a decrease in the response at the top of the reservoir and an increase in the response at the bottom. The reservoir interval is between 1325 and $1350 \mathrm{~m}$ at this location (outlined by the shaded gray area in Figure 5). The change in $\mathrm{G}_{\mathrm{z}}$ is $\pm 8 \mu \mathrm{Gal}$, clearly identifying the position of fluid saturation changes within the reservoir. The sign of the change reflects the changes in the local densities caused by the combined changes in all fluids (oil, brine, and $\mathrm{CO}_{2}$ ).

Popta et al. (1990) showed that a geological structure with a sufficient density contrast can be detected by borehole gravity measurements, if the observation well is not further away than one or two times the thickness of the zone of density contrast. We calculated a borehole gravity response for a $\mathrm{CO}_{2}$ wedge of $250 \mathrm{~m}$ radius and density of $2,260 \mathrm{~kg} / \mathrm{m}^{3}$ (representing $20 \% \mathrm{CO}_{2}$ saturation in $20 \%$ porosity), inside of a $100 \mathrm{~m}$ thick 
sand layer with a density of $2,285 \mathrm{~kg} / \mathrm{m}^{3}$ at a depth of $1 \mathrm{~km}$ (Figure 6a). The background density was $2,160 \mathrm{~kg} / \mathrm{m}^{3}$. Borehole gravity response as a function of distance from the edge of the wedge is shown in Figure 6b. The maximum response at the edge of the $\mathrm{CO}_{2}$ wedge is $10 \mu \mathrm{Gal}$ (due to a $1 \%$ change in density). The responses decrease with distance away from the wedge. Fifty meters away from the wedge, the response is $6 \mu \mathrm{Gal} ; 100 \mathrm{~m}$ away, the response decreases to $4.4 \mu \mathrm{Gal}$; and $200 \mathrm{~m}$ away, the response decreases further, to $2.5 \mu \mathrm{Gal}$. Current borehole gravimeter technology has a repeatability of around $5 \mu \mathrm{Gal}$ for $\mathrm{G}_{z}$ (Thomsen et al., 2003), meaning that with current technology, borehole measurements are sensitive to changes in a zone up to distances equal to a zone thickness away from the zone edge. Note, however, that work on more sensitive borehole gravimeters is ongoing and has the potential to significantly enhance the sensitivity of such devices in the near future (Thomsen et al., 2003).

\section{BRINE FORMATION MODEL}

Saline formations are deep sedimentary rocks saturated with formation waters or brines containing high concentrations of dissolved salts. These formations are widespread and contain enormous quantities of water, but are unsuitable for agriculture or human consumption. These brine-bearing formations are below and hydrologically separated from potable water reservoirs, and have been widely recognized as having high potential for $\mathrm{CO}_{2}$ sequestration. To study the sensitivity of gravity technique to the presence of $\mathrm{CO}_{2}$ in a brine formation, we created a model with a $20 \mathrm{~m}$ thick reservoir at a depth of $1900 \mathrm{~m}$, with porosity of $20 \%$ and variable $\mathrm{CO}_{2}$ and water saturations. The properties of 
the $\mathrm{CO}_{2}$ were calculated assuming hydrostatic pressure at $1900 \mathrm{~m}$ and a temperature of $70^{\circ} \mathrm{C}$, using the NIST14 code. Carbon dioxide is in a gas phase under these pressure and temperature conditions. As noted earlier, these brine formations have not been characterized in the past, and flow simulation models are built based on the stratigraphy and a few logs that might exist in the area; hence, these are simple models. Furthermore, gravity anomalies decay with the inverse square of the distance from their source, thus surface gravity response shows only large-scale changes within the reservoir. This model is representative of the In Salah Carboniferous sandstone reservoir that has been used for storage of about one million tons of $\mathrm{CO}_{2}$ per year (e.g., Wright, 2007, Haddadji, 2006). A mudstone layer of about $900 \mathrm{~m}$ acts as a seal for this reservoir and separates it from a shallow water reservoir.

To simulate a $\mathrm{CO}_{2}$ front with a lateral extent of approximately $1 \mathrm{~km}$, two models were run, one with the $\mathrm{CO}_{2}$ plume at the southeast corner of the model, and one with the $\mathrm{CO}_{2}$ front moved $1 \mathrm{~km}$ northwest. The plume had an $\mathrm{S}_{\mathrm{CO} 2}$ of $30 \%$ and $\mathrm{S}_{\mathrm{w}}$ of $70 \%$, and the initial brine formation had an $\mathrm{S}_{\mathrm{w}}$ of $100 \%$. The density model resulting from this $\mathrm{CO}_{2}$ movement is shown in Figure 7a, whereas the $G_{z}$ response is shown in Figure $7 b$. The movement of the $\mathrm{CO}_{2}$-brine interface produces about a -10 $\mu \mathrm{Gal}$ change in $\mathrm{G}_{\mathrm{z}}$. The same model, but with $90 \% \mathrm{CO}_{2}$ saturation and $10 \%$ water saturation, would produce about a $40 \mu \mathrm{Gal}$ anomaly, whereas a model with $10 \% \mathrm{CO}_{2}$ saturation and $90 \%$ water saturation produces an $-4 \mu \mathrm{Gal}$ response, which is likely on the edge of detectability in the field. For practical considerations, a model with $30 \% \mathrm{CO}_{2}$ saturation and $70 \%$ water saturation would be a lower limit for detection in the field. 
The inversion of $G_{z}$ data shown in Figure 8 clearly identifies the anomalous zone, and the density change was recovered within $30 \%$ of the true value, using synthetic data with no noise added. Almost identical results were obtained when $2.5 \mu \mathrm{Gal}$ of random noise ( $25 \%$ of peak value) was added to the synthetic data. The level of uncertainty in density estimation would decrease if the reservoir was thicker.

\section{COAL MODEL}

Significant potential exists for carbon sequestration and enhanced methane recovery in coalbed methane production scenarios. Our study was motivated by a pilot test planned in the Black Warrior basin in Alabama. Coal seams in the Black Warrior basin are distributed through a thick stratigraphic section and are clustered in a series of coal zones within the Lower Pennsylvanian Pottsville Formation. Assessment of the $\mathrm{CO}_{2}$ sequestration and enhanced recovery potential of coalbed methane in this area indicated that more than 5.9 Tcf of $\mathrm{CO}_{2}$ could be sequestered, while increasing coalbed methane reserves by more than $20 \%$ (Pashin and Clark, 2006). In the area of interest, coalbed methane is produced mainly from the Black Creek, Mary Lee, and Pratt coal zones at depths between 400 and $700 \mathrm{~m}$ and approximately $3 \mathrm{~m}$ thick on average. The permeability of coal in the Black Warrior basin decreases exponentially with depth as overburden stress increases. The permeability of the top layer is $100 \mathrm{mD}$, while the permeability of the deepest layer is around $1 \mathrm{mD}$. The pilot field test will include injecting a total of 1000 tons of $\mathrm{CO}_{2}$ into these three coal zones (300 tons to each zone). 
Flow simulation models (Figure 9) showed that the highest $\mathrm{CO}_{2}$ mole fractions and the largest spatial extent of $\mathrm{CO}_{2}$ exist in the upper two coal layers. $\mathrm{CO}_{2}$ in the deepest layer hardly moved from the injection well, presumably due to very low permeability. The reference model was a coal layer with $95 \%$ water saturation and $5 \%$ residual gas saturation. We assumed that water in fractures is replaced by $\mathrm{CO}_{2}$ and neglected any changes in the matrix density. Figure 10 shows a density variation due to $\mathrm{CO}_{2}$ presence in the uppermost $3 \mathrm{~m}$ thick coal layer at a depth of $400 \mathrm{~m}$ as a function of $\mathrm{x}$ and $\mathrm{y}$ coordinates. Figure 11 shows the surface gravity response of this model. The maximum response is $-4 \mu \mathrm{Gal}$, which is on the edge of detectability in the field. However, if the coal layer thickness was $6 \mathrm{~m}$ instead of $3 \mathrm{~m}$, and the $\mathrm{CO}_{2}$ plume had the same lateral extent, the maximum surface gravity response would be around $-9 \mu \mathrm{Gal}$ and measurable in the field.

As discussed earlier, gravity anomalies decay with the inverse square of the distance from their source, and thus the same $\mathrm{CO}_{2}$ target at a greater depth produces an even smaller surface gravity response (not shown) and would be difficult to detect in the field. The deepest coal layer, around $700 \mathrm{~m}$ in depth, would have to be $18 \mathrm{~m}$ thick for a $\mathrm{CO}_{2}$ anomaly of the same lateral extent and properties described above to be detectable by surface gravity survey.

Figure 12a shows inversion results from surface gravity data shown in Figure 11. The location of the $\mathrm{CO}_{2}$ plume was recovered correctly, although with the smoothing constraint of the inversion, the area was slightly overestimated, resulting in an underestimated value of density change (Figure 12a). The inversion of data with $1 \mu \mathrm{Gal}$ 
random noise (25\% of peak value) results in the correct location of the $\mathrm{CO}_{2}$ plume; however the density contrast cannot be resolved (Figure 12b).

During an industrial size $\mathrm{CO}_{2}$ sequestration, a large volume of $\mathrm{CO}_{2}$ would be injected into the coalbeds. Using the properties of coal and $\mathrm{CO}_{2}$ for the same pressure and temperature conditions as above, we built a model in which the lateral extent of $\mathrm{CO}_{2}$ was several hundred meters. A plan view of the model is shown in Figure 13a; the section view is shown in Figure 13b. The undisturbed coal layer is on the left; a coal layer containing $\mathrm{CO}_{2}$ is on the right. Density of $\mathrm{CO}_{2}$ at a temperature of $35^{\circ} \mathrm{C}(95 \mathrm{~F})$ and a pressure of $600 \mathrm{kPa}$ is $10.6 \mathrm{~kg} / \mathrm{m}^{3}$, using the NIST14 code. Coal densities as a function of $\mathrm{CO}_{2}$ saturation, together with maximum peak surface gravity magnitudes given in Table 1, were calculated using the following formula:

$$
\text { Density }=\left(1-\mathrm{S}_{(\mathrm{CO} 2)}\right) * \text { Density }(\mathrm{coal})+\mathrm{S}_{(\mathrm{CO} 2)} * \operatorname{Density}\left(\mathrm{CO}_{2}\right)
$$

where $\mathrm{S}_{(\mathrm{CO} 2)}$ is $\mathrm{CO}_{2}$ saturation.

The presence of $\mathrm{CO}_{2}$ reduces the coal density, causing the decrease in the gravity response. Adsorption of $\mathrm{CO}_{2}$ into coal can affect the matrix density, and hence the total density change could be smaller than we predicted.

The $G_{z}$ response is defined as the difference between the model with and without $\mathrm{CO}_{2}$ present. Figure 14 shows the surface gravity response (in $\mu \mathrm{Gal}$ ) for $10 \%$ of $\mathrm{CO}_{2}$ saturation. The maximum gravity response is $-14 \mu \mathrm{Gal}$. The contact between the areas with and without $\mathrm{CO}_{2}$ is clearly visible, and the surface gravity response can be measured using current technologies. For the model with $50 \% \mathrm{CO}_{2}$ saturation, the maximum gravity response is $-70 \mu \mathrm{Gal}$, whereas for the model with $90 \% \mathrm{CO}_{2}$ saturation, the maximum gravity response is $-125 \mu \mathrm{Gal}$. 


\section{CONCLUSIONS}

Gravity measurements were modeled for EOR, brine, and coalbed methane formation models. The injection of $\mathrm{CO}_{2}$ produced a bulk density decrease in the reservoir, which in turn produced a reduction in the gravitational attraction from the reservoir. The spatial pattern of the change in the vertical component of gravity $\left(\mathrm{G}_{\mathrm{z}}\right)$ was directly correlated with the net change in reservoir density. Furthermore, time-lapse changes in the borehole $G_{z}$ clearly identified the vertical section of the reservoir where fluid saturations are changing.

EOR reservoirs represent the most difficult case of possible sequestration scenarios, because of the relatively thin injection interval and the multiple fluid components present. In our simulations, changes in the vertical component of gravity on the surface caused by $\mathrm{CO}_{2}$ injection over a 20 -year period were below the level of repeatability for current field surveys. However, measurements made in boreholes just above the reservoir interval were sensitive enough to observe measurable changes in $G_{z}$ as $\mathrm{CO}_{2}$ injection proceeded. Inversion of such measurements made in numerous wells could map the areas of net density changes caused by injected $\mathrm{CO}_{2}$ and water within the reservoir.

The $\mathrm{CO}_{2}$-brine front, on the order of $1 \mathrm{~km}$ within a $20 \mathrm{~m}$ thick brine formation at $1900 \mathrm{~m}$ depth, with $30 \% \mathrm{CO}_{2}$ and $70 \%$ brine saturations, respectively, produced a -10 $\mu$ Gal surface gravity anomaly. We would expect such an anomaly to be detectable in the field. 
The pilot test size amount of $\mathrm{CO}_{2}$ in a coalbed methane reservoir did not produce a large enough surface gravity response; however, we would expect that for an industrial size injection, the response would be measurable on the surface.

Gravity inversions in all three scenarios illustrated that, provided we could collect high quality gravity data in the field, and we have some a priori information about the depth of the reservoir, we can recover the general position of density changes caused by $\mathrm{CO}_{2}$ presence, but not the absolute value of the change.

Although at shallow depths and lower pressures $\mathrm{CO}_{2}$ has gas-like properties, since brine formations are commonly found above gas or oil reservoirs, gravity monitoring could still be useful for leak detection.

The gravity technique presented here showed enough promise, as a low-cost supplement to seismic monitoring, to justify further evaluation and testing under a wider range of conditions. Borehole gravity measurements should be used in conjunction with pressure test data and/or surface seismic data, to provide a basis for statistical interpolation of predicted changes in $\mathrm{S}_{\mathrm{CO} 2}$. This may provide a low-cost way of monitoring changes within the reservoir, with only the initial 3D seismic survey being relatively expensive.

\section{ACKNOWLEDGMENTS}

This work was supported in part by a Cooperative Research and Development Agreement between BP Corporation North America, as part of the $\mathrm{CO}_{2}$ Capture Project

of the Joint Industry Program, and the U.S. Department of Energy through the National 
Energy Technologies Laboratory, and by the Ernest Orlando Lawrence Berkeley National Laboratory, managed by the University of California for the U.S. Department of Energy under contract DE-AC02-05CH11231. We would like to thank Xiong Li, John Ferguson and two anonymous reviewers for suggestions and comments that helped us to improve this manuscript.

\section{REFERENCES}

Brown, J. M., T. Chen, T. M. Niebauer, F. J. Klopping, J. Ferguson, and J. Brady, 2003, Absolute and relative gravity integration for high precision 4D reservoir monitoring: EAGE Expanded Abstracts, A26-A26.

Gasperikova, E., and M. Hoversten, 2006, A Feasibility Study of Non-seismic Geophysical Methods for Monitoring Geologic $\mathrm{CO}_{2}$ Sequestration: The Leading Edge, 25, 1282-1288.

Haddadji, R., 2006, The In Salah CCS experience, Sonatrach, Algeria: The first international conference on the clean development mechanism, EU-OPEC Roundtable on carbon dioxide capture \& storage, Riyadh, Saudi Arabia, http://www.opec.org/home/Press\%20Room/EU-OPEC\%20presentations/Haddadji Sonatrach \%20Algeria.pdf, accessed August 12, 2008..

Hare, J.L., J.F. Ferguson, and C.L.V. Aiken, 1999, The 4-D Microgravity Method for 
Waterflood Surveillance: A Model Study from the Prudhoe Bay Reservoir, Alaska: Geophysics, 64, 78-87.

NIST Mixture Property Database, NIST Standard Reference Database \#14, 1992, U.S. Department of Commence, National Institute of Standards and Technology (NIST).

Nooner, S.L., M.A. Zumberge, O. Eiken, T. Stenvold, and G.S. Sasagawa, 2003, Seafloor Micro-gravity Survey of the Sleipner $\mathrm{CO}_{2}$ Sequestration Site: EOS Trans. AGU, 84(46), Fall Meet. Suppl., Abstract GC31A-01.

Pashin, J.C., and P.E. Clark, 2006, SECARB Field Test for $\mathrm{CO}_{2}$ Sequestration in Coalbed Methane Reservoirs of the Black Warrior Basin: Tuscaloosa, Alabama, University of Alabama, College of Continuing Studies, 2006 International Coalbed Methane Symposium Proceedings, paper 0630.

Popta, J.V., J.M.T. Heywood, S.J. Adams, and D.R. Bostock, 1990, Use of Borehole Gravimetry for Reservoir Characterization and Fluid Saturation Monitoring: SPE 20896, 151- 160.

Smith, J.T., G.M. Hoversten, E. Gasperikova, and H.F. Morrison, 1999. Sharp Boundary Inversion of 2-D Magnetotelluric Data: Geophysical Prospecting, 47, 469-486.

Thomsen, L. A., J. L. Brady, E. Biegert, and K. M. Strack, 2003, A novel approach to 4D 
full field density monitoring: SEG Annual Meeting Research Workshop, MC 1.4, 2003.

Wright, I. W., 2007, The Insalah Project: $\mathrm{CO}_{2}$ storage monitoring and verification: Carbon Sequestration Leadership Forum, Paris, France, http://www.cslforum.org/ documents/InSalahProjectPoster0307.pdf, accessed August 12, 2008. 


\section{LIST OF FIGURES}

Figure 1a. Plan view of the net change in density $\left(\mathrm{kg} / \mathrm{m}^{3}\right)$ within the reservoir after 20 years of $\mathrm{CO}_{2}$ injection. Location of 22 wells is indicated by black symbols. Cool colors represent density increase while warm colors represent density decrease.

Figure 1b. Plan view of the net change in $\mathrm{S}_{\mathrm{CO} 2}$ within the reservoir after 20 years of $\mathrm{CO}_{2}$ injection $\left(\mathrm{S}_{\mathrm{CO} 2}=1\right.$ is $100 \%$ of $\mathrm{CO}_{2}, \mathrm{~S}_{\mathrm{CO} 2}=0$ is $0 \%$ of $\mathrm{CO}_{2}$. $)$ Location of 22 wells is indicated by black symbols. Cool colors represent low $\mathrm{CO}_{2}$ saturations while warm colors represent high $\mathrm{CO}_{2}$ saturations.

Figure 2. Plan view of the change in $\mathrm{G}_{\mathrm{z}}(\mu \mathrm{Gal})$ at a depth of $1200 \mathrm{~m}$ after 20 years of $\mathrm{CO}_{2}$ injection using 22 wells indicated by black symbols. Warm colors represent decrease in $G_{z}$, whereas cool colors represent $G_{z}$ increase.

Figure 3. Inversion of $\mathrm{G}_{\mathrm{z}}$ data in Figure 2. Black symbols indicate locations of 22 wells. Cool colors represent density increase $\left(\mathrm{kg} / \mathrm{m}^{3}\right)$, whereas warm colors represent density decrease.

Figure 4a. Change in $\mathrm{S}_{\mathrm{w}}$ after 20 years of $\mathrm{CO}_{2}$ injection. Dark colors indicate an increase in $\mathrm{S}_{\mathrm{w}}$, light colors represent a decrease in $\mathrm{S}_{\mathrm{w}}$. Black open squares indicate borehole gravimeter locations. 
Figure 4b. Change in $\mathrm{S}_{\mathrm{CO} 2}$ after 20 years of $\mathrm{CO}_{2}$ injection. Dark colors indicate an increase in $\mathrm{S}_{\mathrm{CO} 2}$; light colors represent a decrease in $\mathrm{S}_{\mathrm{CO} 2}$. Black open squares indicate borehole gravimeter locations.

Figure 5. Change in borehole vertical profile of $\mathrm{G}_{\mathrm{z}}(\mu \mathrm{Gal})$ over 20 years of $\mathrm{CO}_{2}$ injection. The reservoir interval is indicated by the light gray area.

Figure 6a. $\mathrm{CO}_{2}$ wedge of $250 \mathrm{~m}$ radius and density of $2,260 \mathrm{~kg} / \mathrm{m}^{3}$ (representing $20 \%$ $\mathrm{CO}_{2}$ saturation in $20 \%$ porosity) inside of a $100 \mathrm{~m}$ thick sand layer with a density of $2,285 \mathrm{~kg} / \mathrm{m}^{3}$ at a depth of $1 \mathrm{~km}$. The background density is $2,160 \mathrm{~kg} / \mathrm{m}^{3}$.

Figure 6b. Borehole gravity response $(\mu \mathrm{Gal})$ of the model in Figure 6 a as a function of distance from the wedge edge.

Figure 7a. Model of $1 \mathrm{~km}$ wide $\mathrm{CO}_{2}$ front in $20 \mathrm{~m}$ thick brine formation with $20 \%$ porosity at the depth of $1900 \mathrm{~m} . \mathrm{CO}_{2}$ plume with $30 \%$ of $\mathrm{CO}_{2}$ and $70 \%$ of water is moving northwest.

Figure 7b. Surface gravity response $(\mu \mathrm{Gal})$ of the model in Figure $7 \mathrm{a}$ as a function of $\mathrm{x}$ and y coordinates.

Figure 8. Density change $\left(\mathrm{kg} / \mathrm{m}^{3}\right)$ as a function of $\mathrm{x}$ and $\mathrm{y}$ coordinates recovered by inversion of Gz data shown in Figure $7 b$. 
Figure 9: Plan view of $\mathrm{CO}_{2}$ mole fractions for the coal layer at a depth of $400 \mathrm{~m}$ (from Sproule Associates).

Figure 10: Plan view of a density model $\left(\mathrm{kg} / \mathrm{m}^{3}\right)$ based on the flow simulation model in Figure 9.

Figure 11: Surface gravity response ( $\mu \mathrm{Gal})$ of the model in Figure 10.

Figure 12a. Density change $\left(\mathrm{kg} / \mathrm{m}^{3}\right)$ as a function of $\mathrm{x}$ and $\mathrm{y}$ coordinates recovered by inversion of the $G_{z}$ data shown in Figure 11.

Figure 12b. Density change $\left(\mathrm{kg} / \mathrm{m}^{3}\right)$ as a function of $\mathrm{x}$ and $\mathrm{y}$ coordinates recovered by inversion of the $\mathrm{G}_{\mathrm{z}}$ data in Figure 11 with $1 \mu \mathrm{Gal}$ random noise (25\% of peak response) added.

Figure 13a: Plan view of a density model with a coal layer with no $\mathrm{CO}_{2}$ on the left and with $\mathrm{CO}_{2}$ on the right.

Figure 13b: Cross-section of a density model with a coal layer with no $\mathrm{CO}_{2}$ on the left and with $\mathrm{CO}_{2}$ on the right. 
Figure 14: Surface gravity response ( $\mu \mathrm{Gal}$ ) for the coal layer in Figure 13 with $10 \% \mathrm{CO}_{2}$ saturation. 
Table 1: Coal layer density as a function of $\mathrm{CO}_{2}$ saturation at a temperature of $35^{\circ} \mathrm{C}$ and pressure of $600 \mathrm{kPa}$.

\begin{tabular}{|c|c|c|}
\hline \% $\mathrm{CO}_{\mathbf{2}}$ & Density $\left(\mathbf{k g} / \mathbf{m}^{\mathbf{3}}\right)$ & $\begin{array}{c}\text { Peak Gravity Response } \\
(\boldsymbol{\mu} \text { Gal })\end{array}$ \\
\hline 0 & 1435.0 & 0 \\
\hline 10 & 1292.6 & -14 \\
\hline 50 & 722.8 & -70 \\
\hline 70 & 437.9 & -98 \\
\hline 80 & 295.5 & -112 \\
\hline 90 & 153.0 & -125 \\
\hline
\end{tabular}




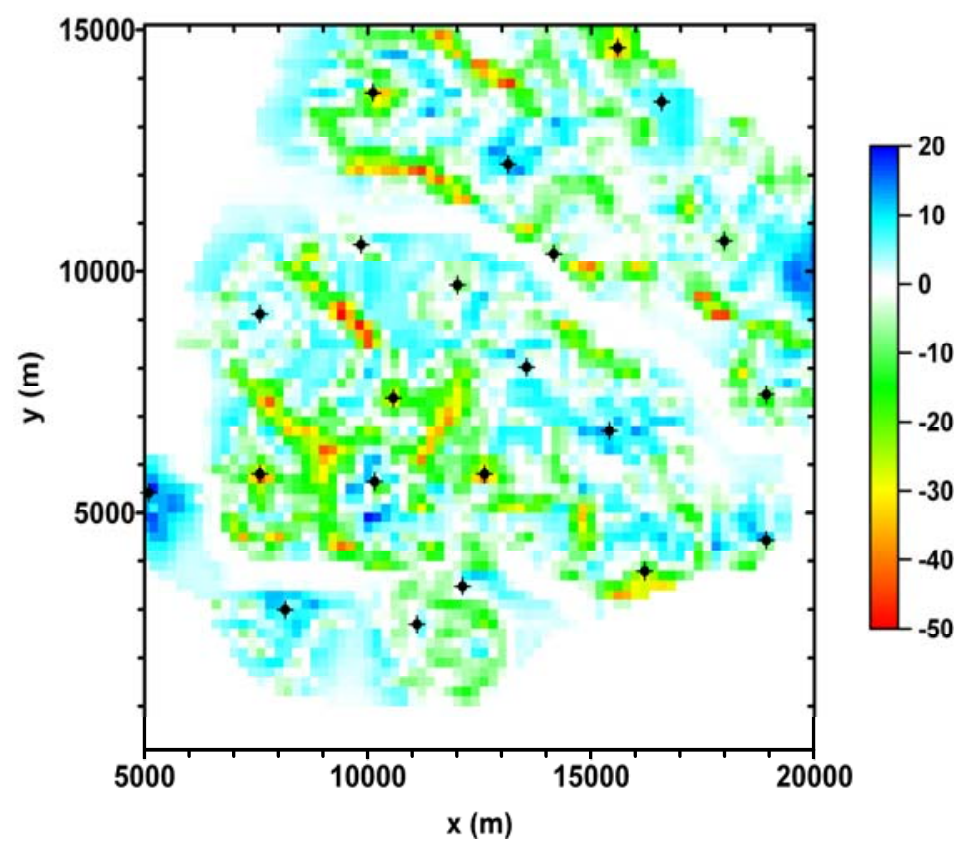

Figure 1a. Plan view of the net change in density $\left(\mathrm{kg} / \mathrm{m}^{3}\right)$ within the reservoir after 20 years of $\mathrm{CO}_{2}$ injection. Location of 22 wells is indicated by black symbols. Cool colors represent a density increase while warm colors represent the density decrease.

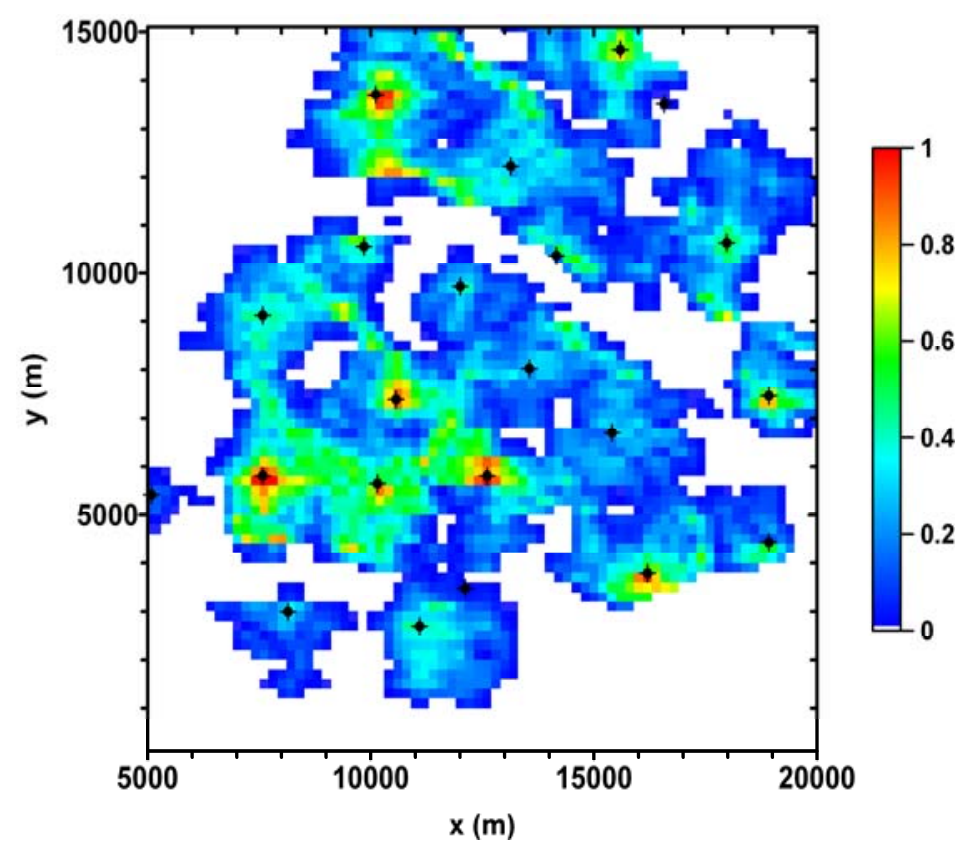

Figure 1b. Plan view of the net change in $\mathrm{S}_{\mathrm{CO} 2}$ within the reservoir after 20 years of $\mathrm{CO}_{2}$ injection $\left(\mathrm{S}_{\mathrm{CO} 2}=1\right.$ is $100 \%$ of $\mathrm{CO}_{2}, \mathrm{~S}_{\mathrm{CO} 2}=0$ is $0 \%$ of $\mathrm{CO}_{2}$.) Location of 22 wells is indicated by black symbols. Cool colors represent low $\mathrm{CO}_{2}$ saturations while warm colors represent high $\mathrm{CO}_{2}$ saturations. 


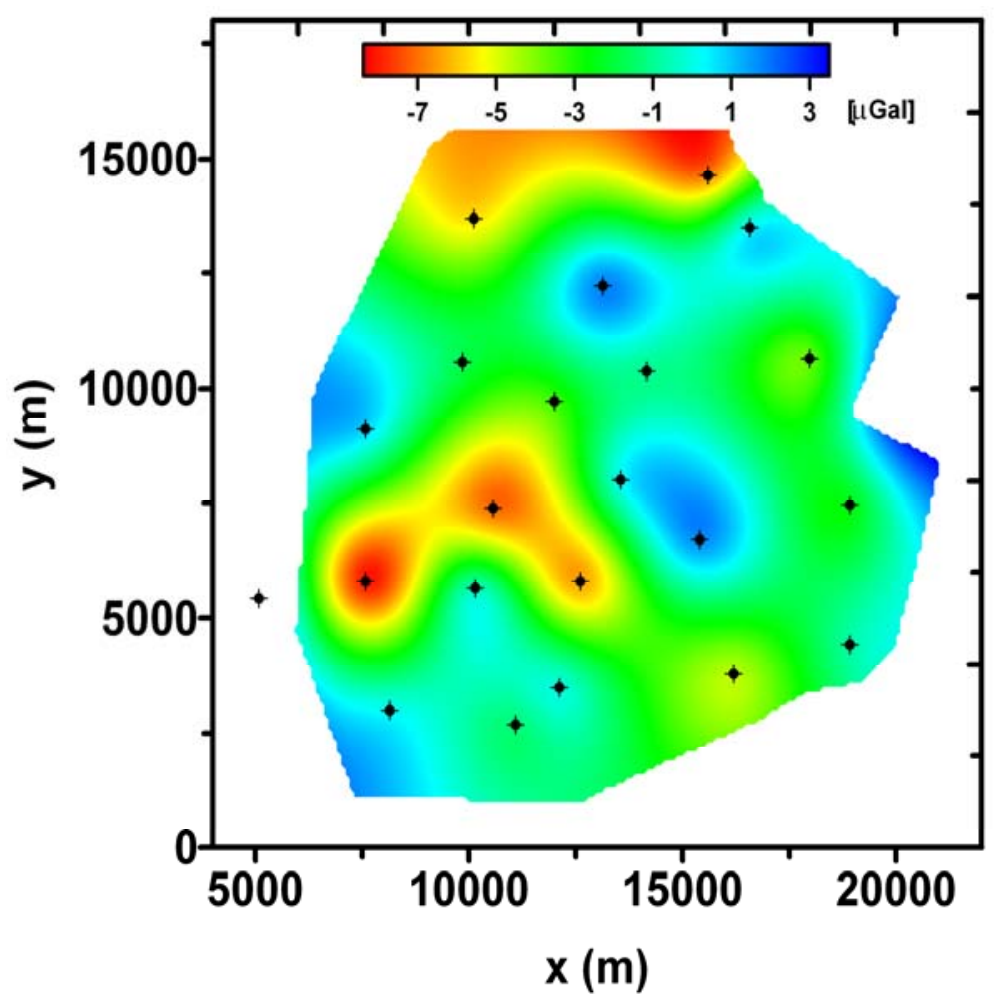

Figure 2. Plan view of the change in $\mathrm{G}_{\mathrm{z}}(\mu \mathrm{Gal})$ at a depth of $1200 \mathrm{~m}$ after 20 years of $\mathrm{CO}_{2}$ injection using 22 wells indicated by black symbols. Warm colors represent decrease in $\mathrm{G}_{\mathrm{z}}$, whereas cool colors represent $\mathrm{G}_{\mathrm{z}}$ increase. 


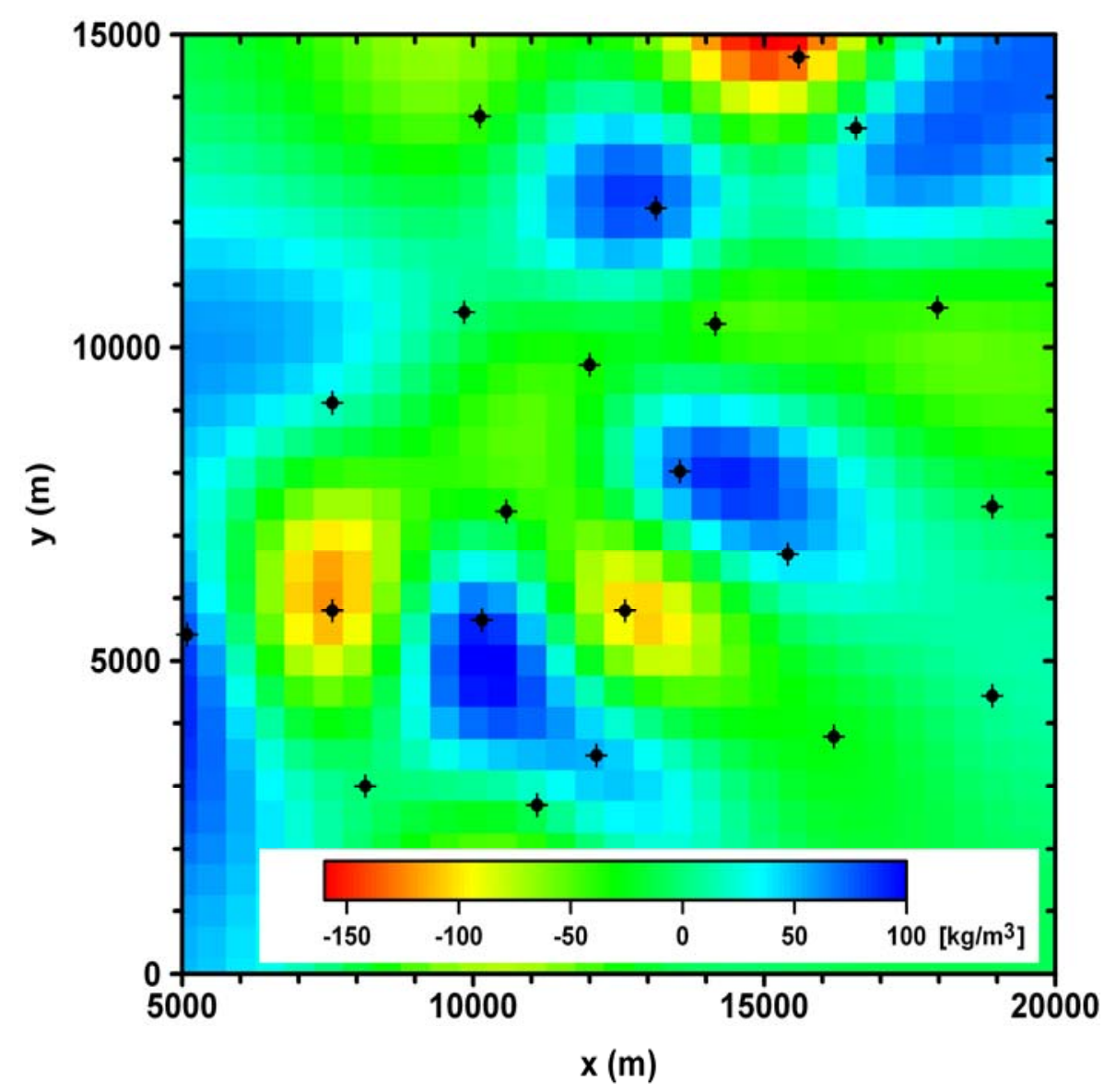

Figure 3. Inversion of $\mathrm{G}_{\mathrm{z}}$ data in Figure 2. Black symbols indicate locations of 22 wells. Cool colors represent density increase $\left(\mathrm{kg} / \mathrm{m}^{3}\right)$, whereas warm colors represent density decrease. 


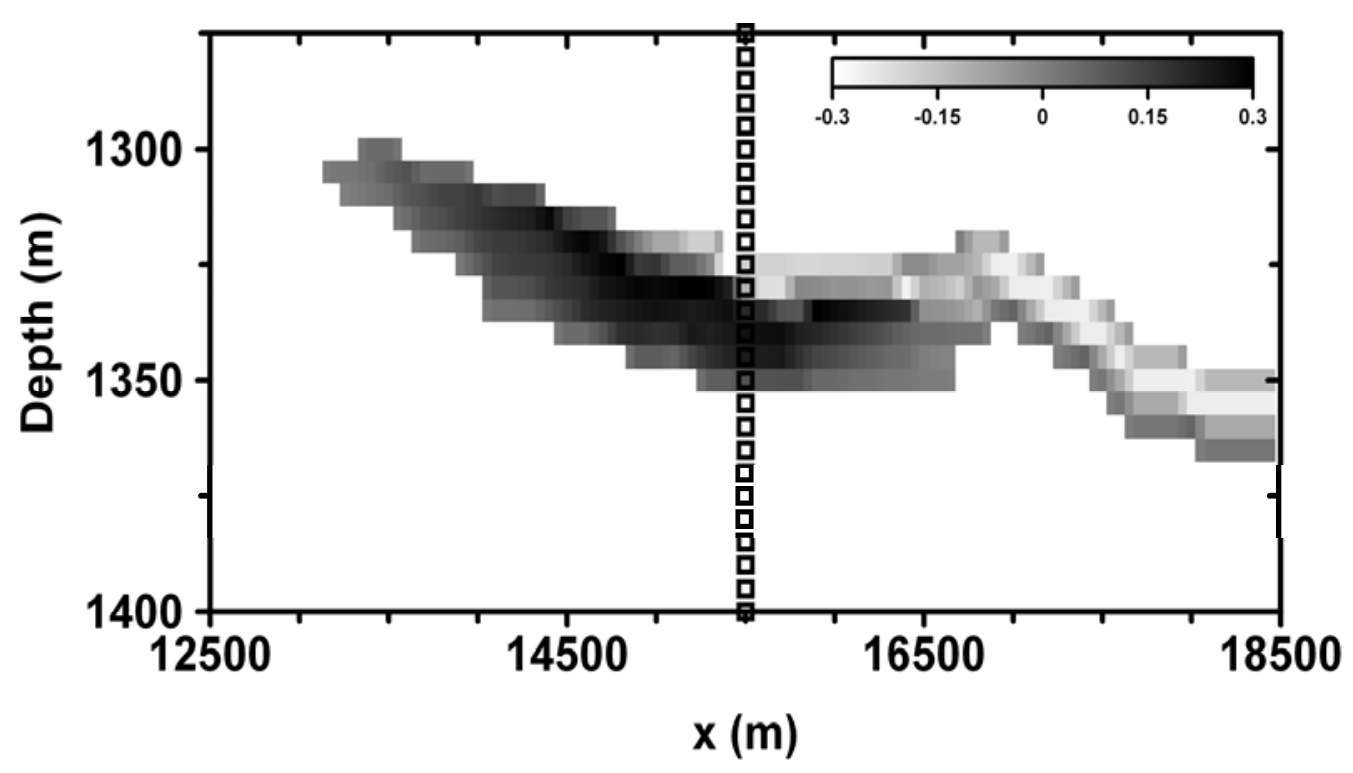

Figure 4a. Change in $\mathrm{S}_{\mathrm{w}}$ after 20 years of $\mathrm{CO}_{2}$ injection. Dark colors indicate an increase in $\mathrm{S}_{\mathrm{w}}$, light colors represent a decrease in $\mathrm{S}_{\mathrm{w}}$. Black open squares indicate borehole gravimeter locations.

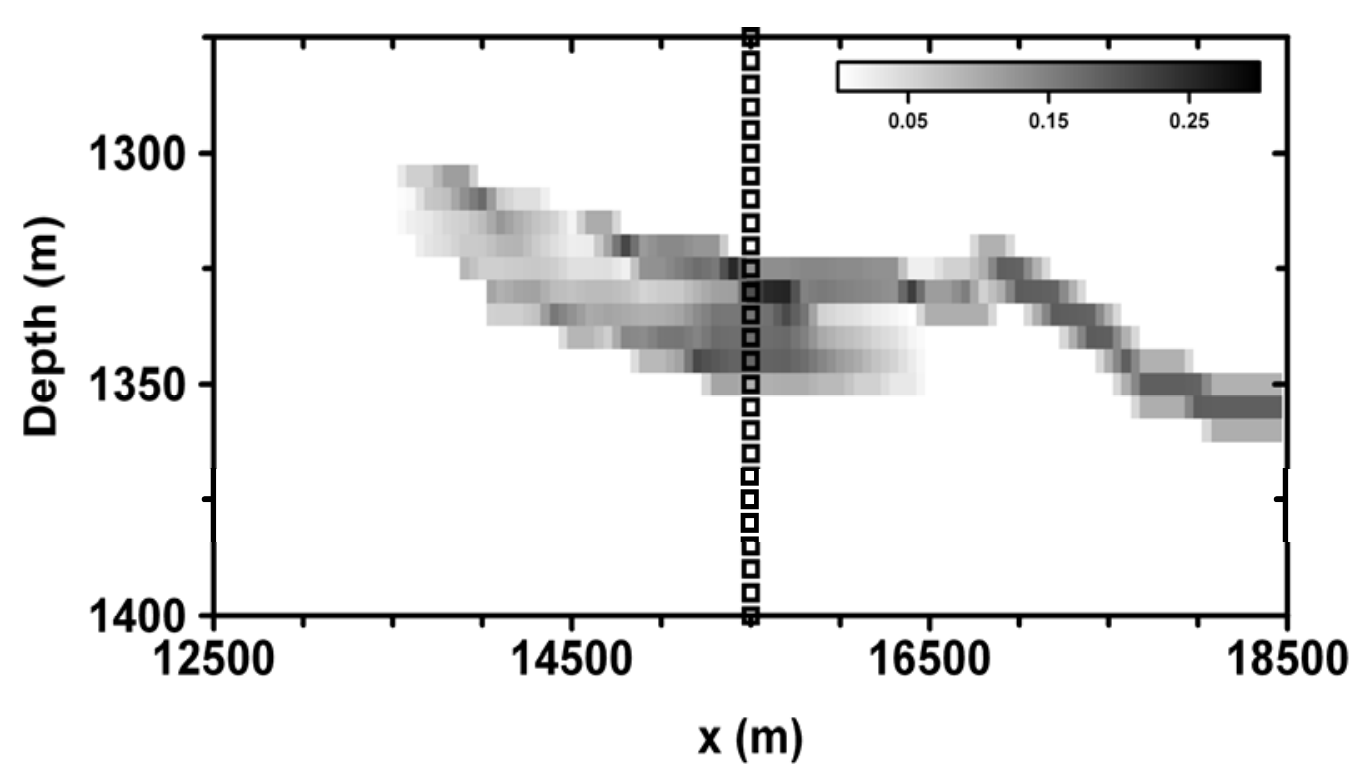

Figure 4b. Change in $\mathrm{S}_{\mathrm{CO} 2}$ after 20 years of $\mathrm{CO}_{2}$ injection. Dark colors indicate an increase in $\mathrm{S}_{\mathrm{CO} 2}$; light colors represent a decrease in $\mathrm{S}_{\mathrm{CO} 2}$. Black open squares indicate borehole gravimeter locations. 


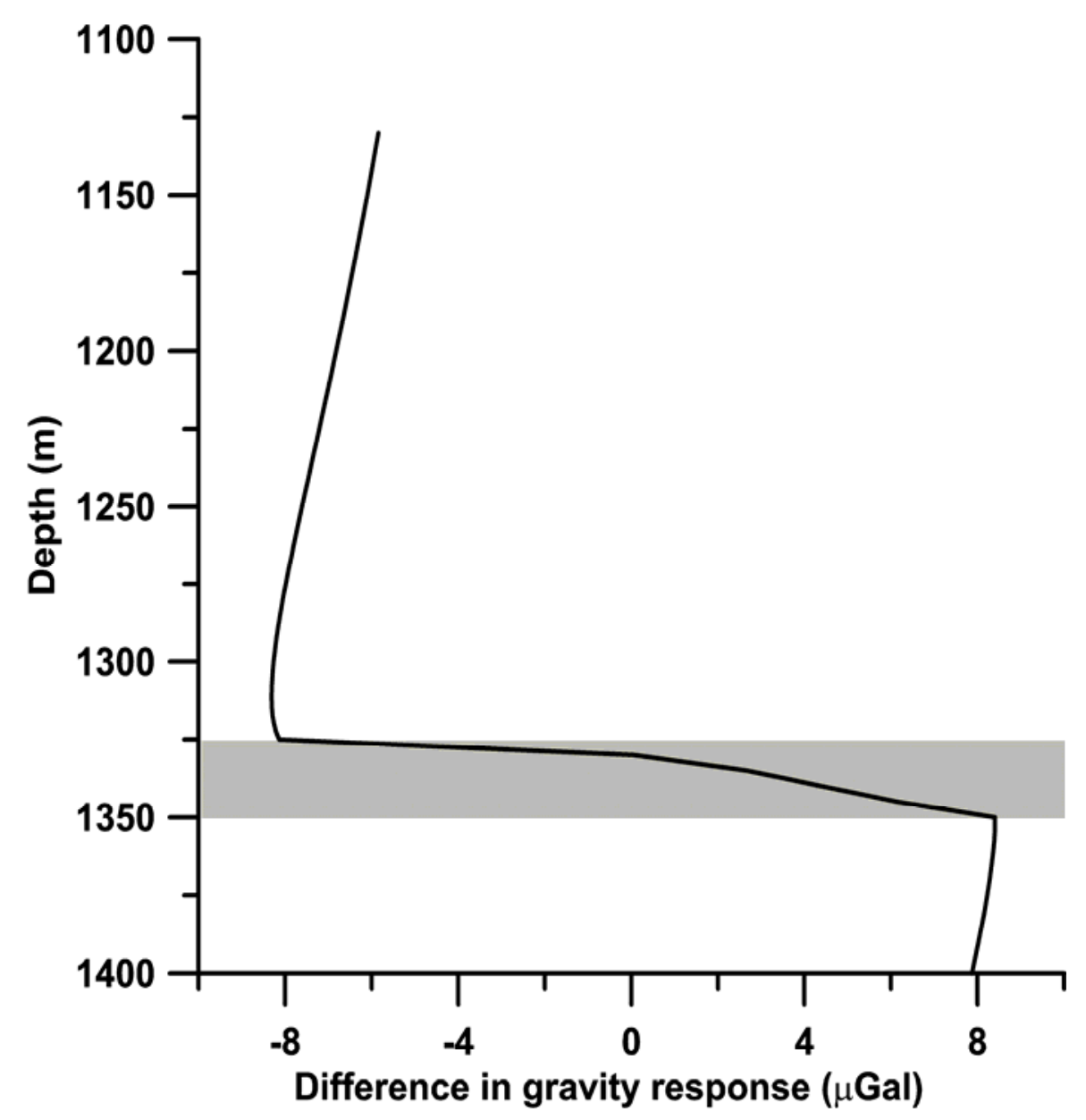

Figure 5. Change in borehole vertical profile of $\mathrm{G}_{\mathrm{z}}(\mu \mathrm{Gal})$ over 20 years of $\mathrm{CO}_{2}$ injection. The reservoir interval is indicated by the light gray area. 


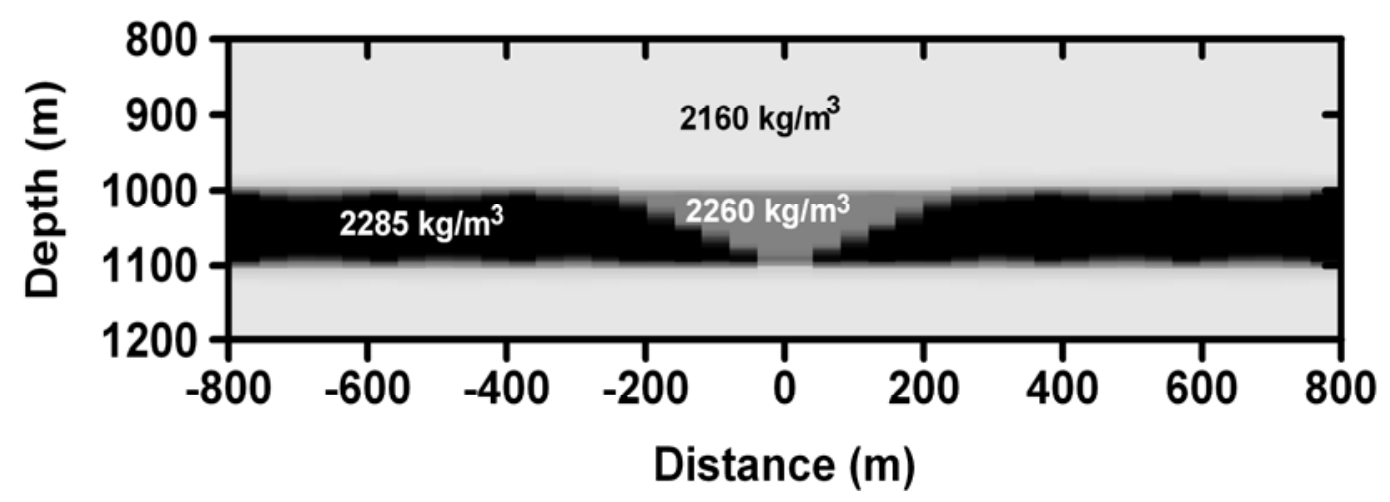

Figure 6a. $\mathrm{CO}_{2}$ wedge of $250 \mathrm{~m}$ radius and density of $2,260 \mathrm{~kg} / \mathrm{m}^{3}$ (representing $20 \%$ $\mathrm{CO}_{2}$ saturation in $20 \%$ porosity) inside of a $100 \mathrm{~m}$ thick sand layer with a density of $2,285 \mathrm{~kg} / \mathrm{m}^{3}$ at a depth of $1 \mathrm{~km}$. The background density is $2,160 \mathrm{~kg} / \mathrm{m}^{3}$.

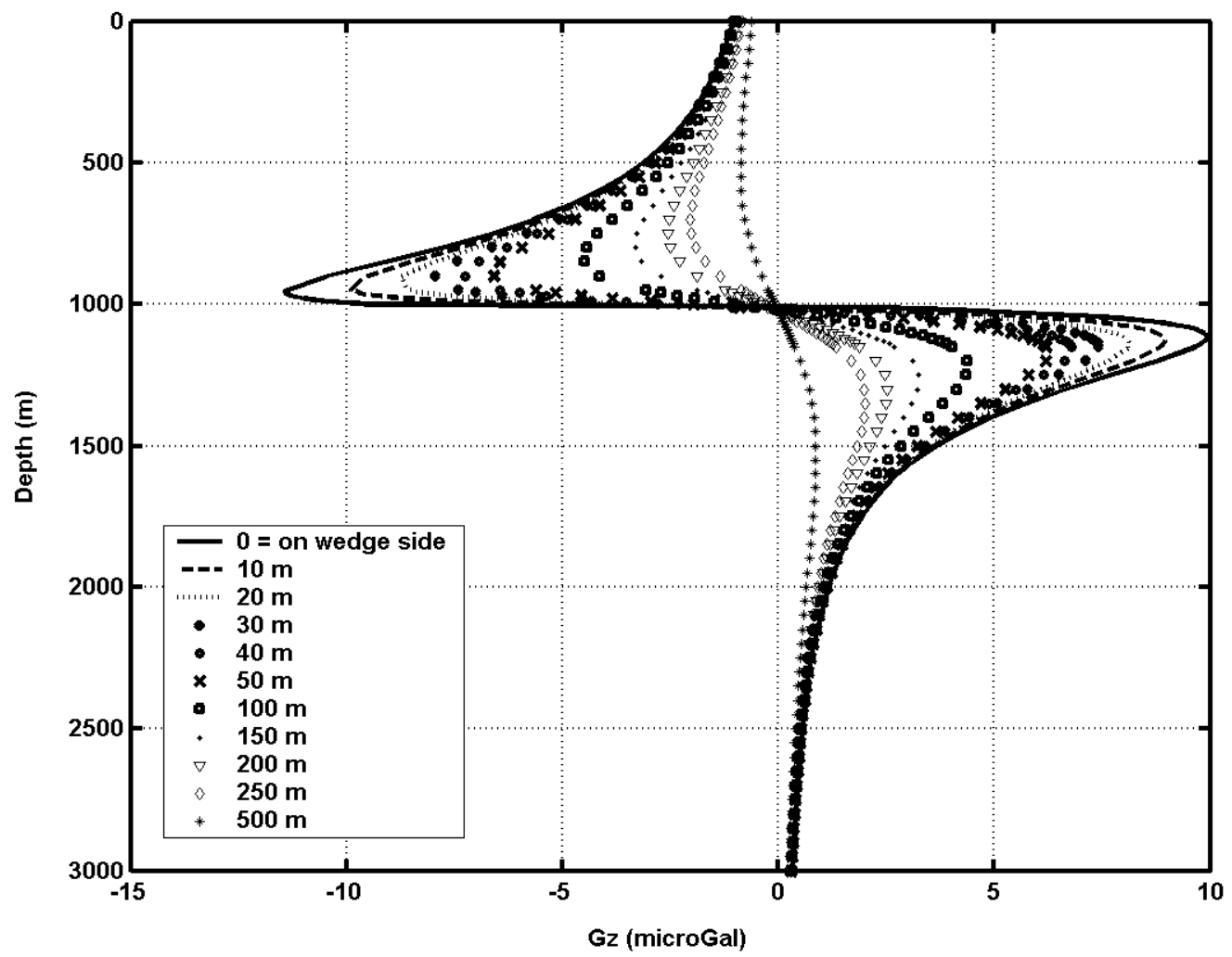

Figure $6 \mathbf{b}$. Borehole gravity response $(\mu \mathrm{Gal})$ of the model in Figure $6 \mathrm{a}$ as a function of distance from the wedge edge. 


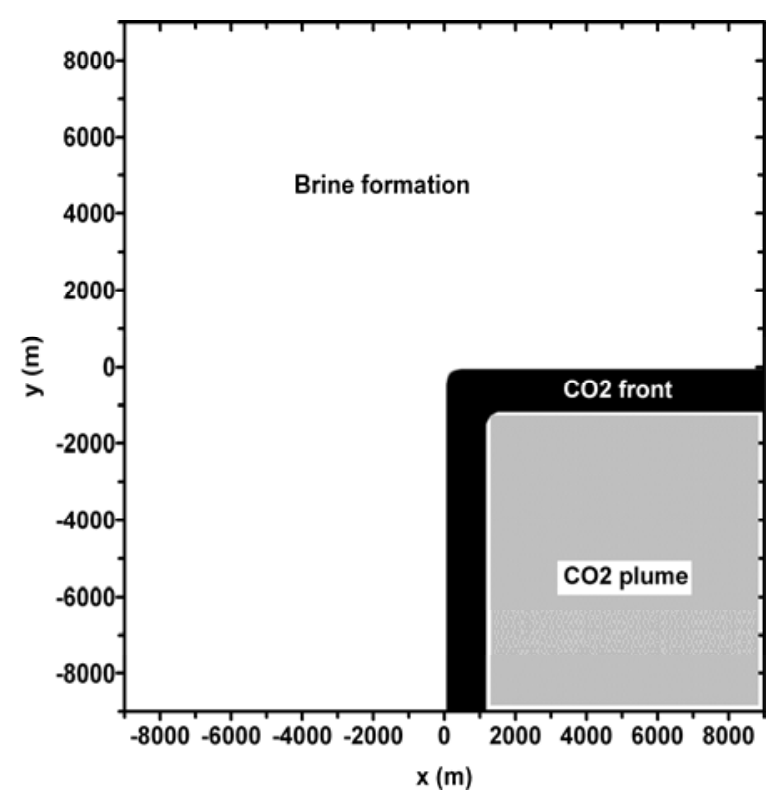

Figure 7a. Model of $1 \mathrm{~km}$ wide $\mathrm{CO}_{2}$ front in $20 \mathrm{~m}$ thick brine formation with $20 \%$ porosity at the depth of $1900 \mathrm{~m} . \mathrm{CO}_{2}$ plume with $30 \%$ of $\mathrm{CO}_{2}$ and $70 \%$ of water is moving northwest.

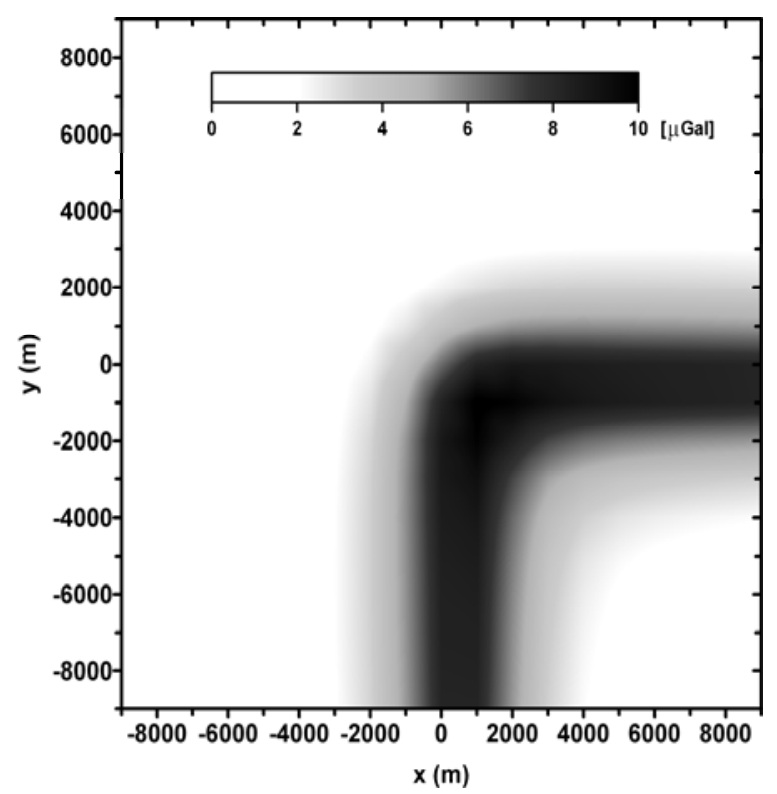

Figure 7b. Surface gravity response $(\mu \mathrm{Gal})$ of the model in Figure $7 \mathrm{a}$ as a function of $\mathrm{x}$ and y coordinates. 


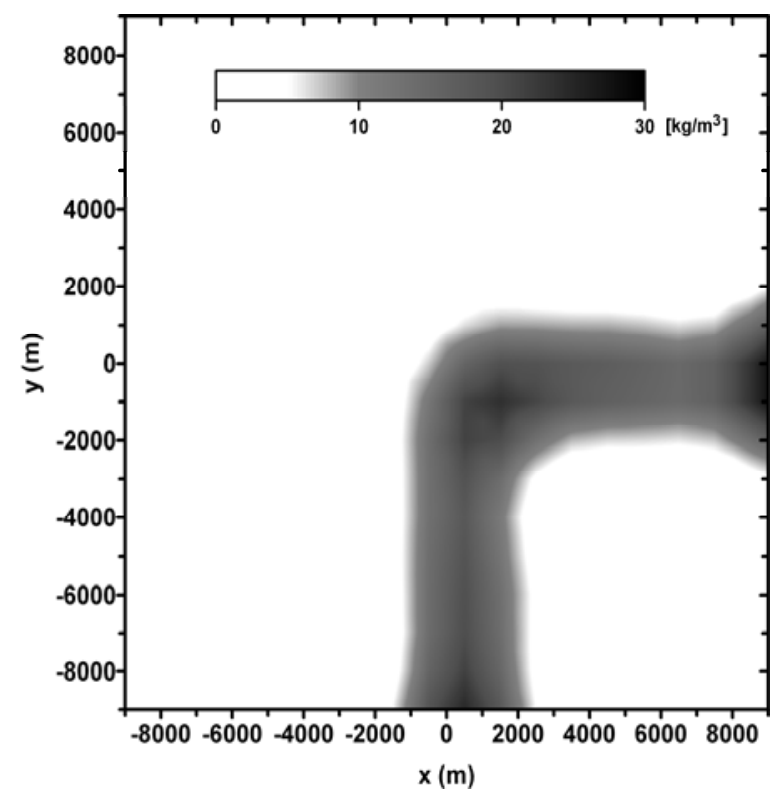

Figure 8. Density change $\left(\mathrm{kg} / \mathrm{m}^{3}\right)$ as a function of $\mathrm{x}$ and $\mathrm{y}$ coordinates recovered by inversion of $\mathrm{Gz}$ data shown in Figure $7 \mathrm{~b}$. 


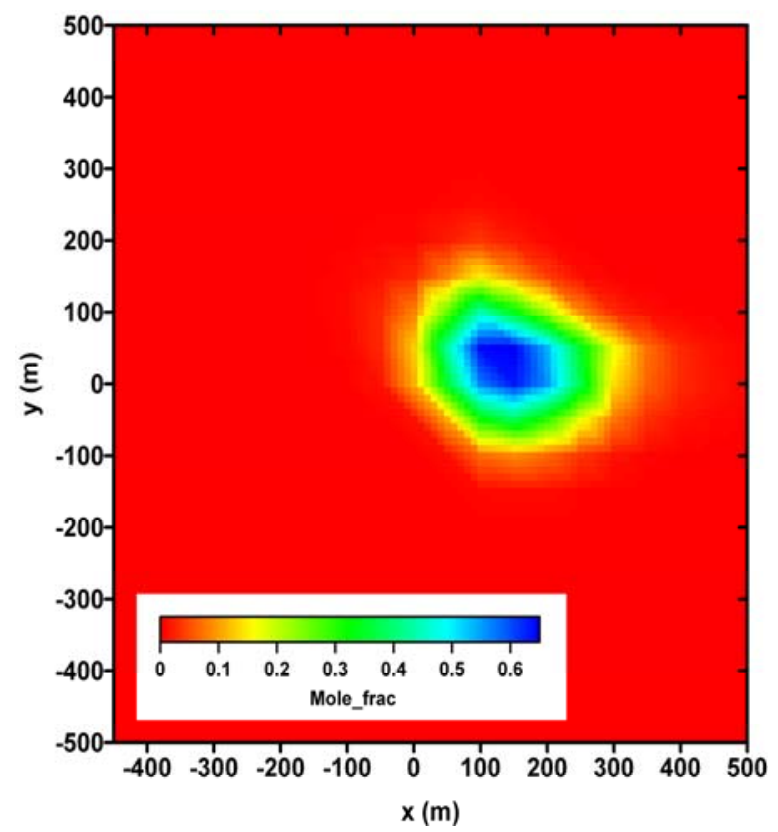

Figure 9: Plan view of $\mathrm{CO}_{2}$ mole fractions for the coal layer at a depth of $400 \mathrm{~m}$ (from Sproule Associates) 


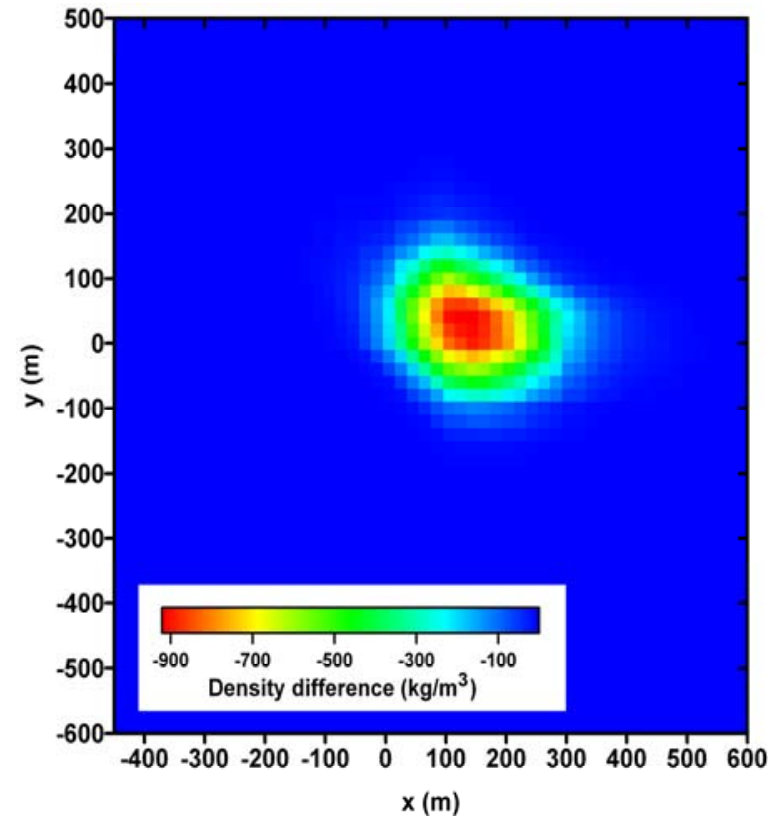

Figure 10: Plan view of a density model $\left(\mathrm{kg} / \mathrm{m}^{3}\right)$ based on the flow simulation model in Figure 9. 


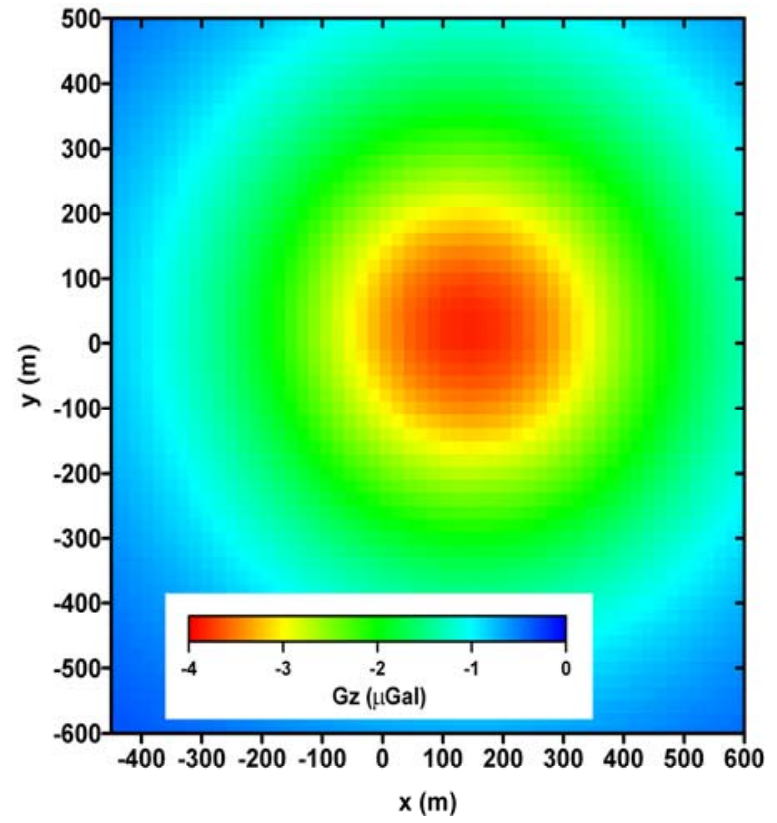

Figure 11: Surface gravity response ( $\mu \mathrm{Gal})$ of the model in Figure 10. 


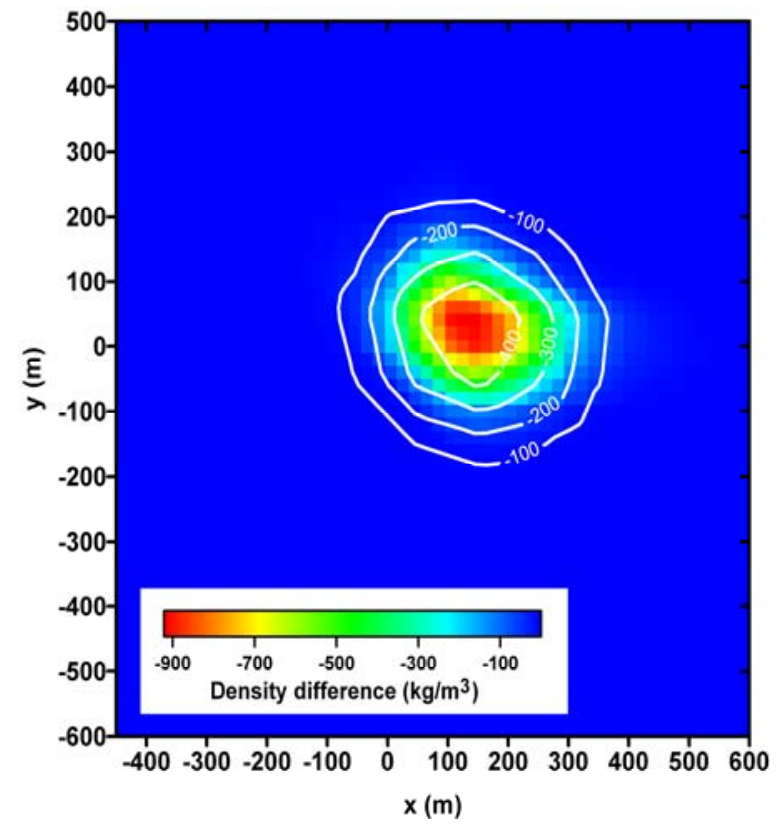

Figure 12a. Density change $\left(\mathrm{kg} / \mathrm{m}^{3}\right)$ as a function of $\mathrm{x}$ and $\mathrm{y}$ coordinates recovered by inversion of the $\mathrm{G}_{\mathrm{z}}$ data shown in Figure 11 .

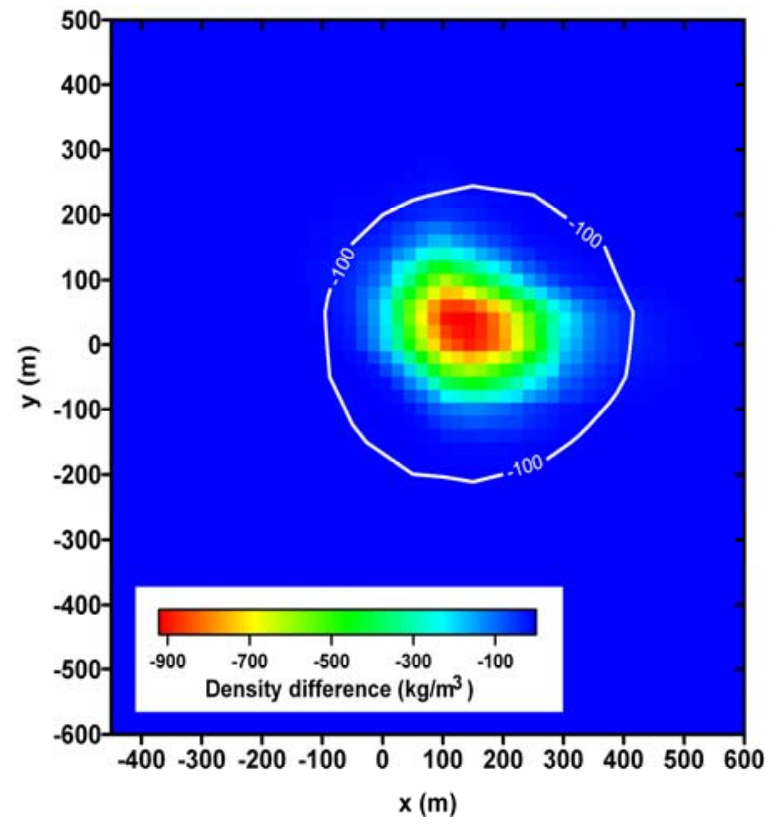

Figure 12b. Density change $\left(\mathrm{kg} / \mathrm{m}^{3}\right)$ as a function of $\mathrm{x}$ and $\mathrm{y}$ coordinates recovered by inversion of the $G_{z}$ data in Figure 11 with $1 \mu \mathrm{Gal}$ random noise ( $25 \%$ of peak response) added. 


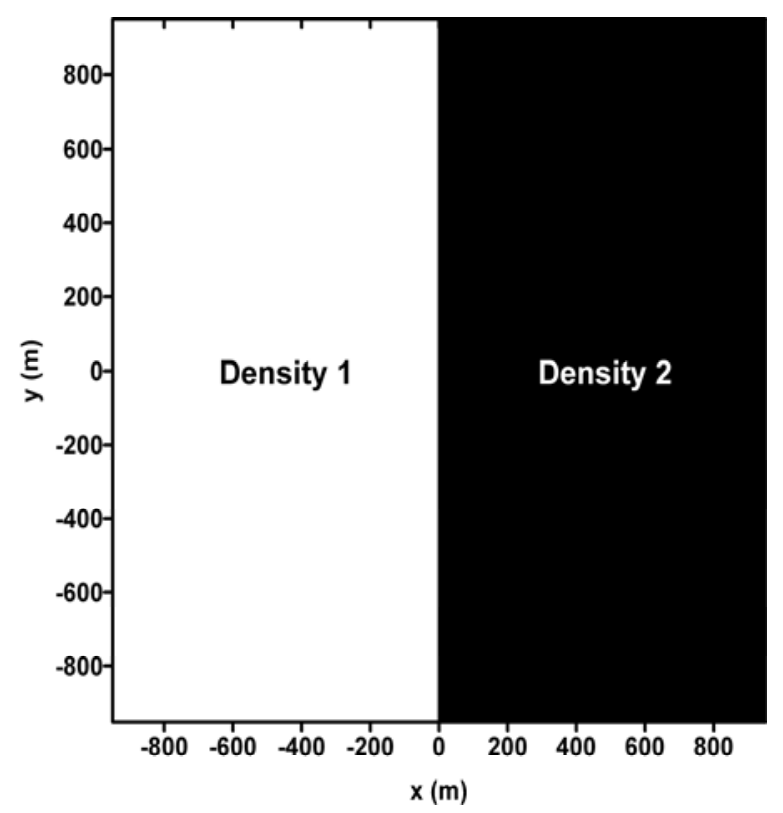

Figure 13a: Plan view of a density model with a coal layer with no $\mathrm{CO}_{2}$ on the left and with $\mathrm{CO}_{2}$ on the right.

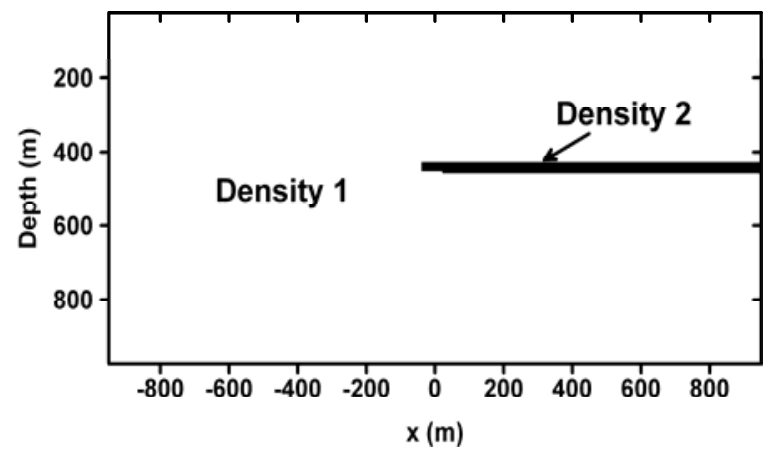

Figure 13b: Cross-section of a density model with a coal layer with no $\mathrm{CO}_{2}$ on the left and with $\mathrm{CO}_{2}$ on the right. 


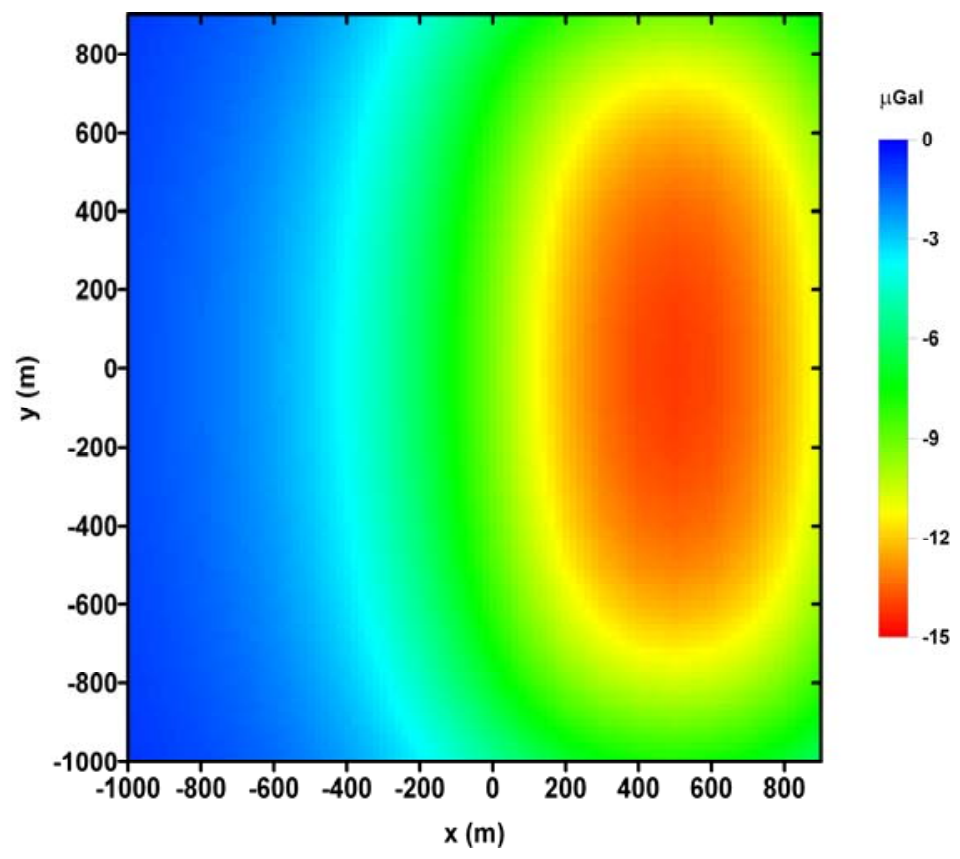

Figure 14: Surface gravity response $(\mu \mathrm{Gal})$ for the coal layer in Figure 13 with $10 \% \mathrm{CO}_{2}$ saturation. 